\title{
Erratum to: Photoelectron Thermometry as a Novel Method to Measure Thermodynamic Temperature
}

\author{
I. Kinoshita • J. Ishii
}

Published online: 10 September 2011

(C) Springer Science+Business Media, LLC 2011

\section{Erratum to: Int J Thermophys (2011) 32:1387-1398 DOI 10.1007/s10765-011-1027-6}

The Corresponding author name was erroneously published as I. Kinosnita. The correct name is I. Kinoshita.

The online version of the original article can be found under doi:10.1007/s10765-011-1027-6.

\section{Kinoshita $(\varangle)$}

Graduate School of Nano System Science, Yokohama City University, Seto 22-2, Kanazawaku, Yokohama 236-0027, Japan

e-mail: ikinoshi@yokohama-cu.ac.jp

J. Ishii

National Metrology Institute of Japan AIST, Umezono 1-1-1, Tsukuba 305-8563, Japan 